\title{
Total Number of Study Animals Purchased
}

National Cancer Institute

\section{Source}

National Cancer Institute. Total Number of Study Animals Purchased. NCI Thesaurus.

Code C130198.

The absolute count of all animals bought for an intended purpose within a study. 